\title{
ppGpp and cytotoxicity diversity in Shiga toxin-producing Escherichia coli (STEC) isolates - CORRIGENDUM - ERRATUM
}

\section{Erratum}

Cite this article: Stella AE, Luz D, Piazza RMF, Spira B (2018). ppGpp and cytotoxicity diversity in Shiga toxin-producing Escherichic coli (STEC) isolates - CORRIGENDUM ERRATUM. Epidemiology and Infection 146, 407-407. https://doi.org/10.1017/ S0950268817002886
A. E. Stella, D. Luz, R. M. F. Piazza and B. Spira

doi: 10.1017/S095026881700200X, Published online: 11 September 2017

In the above-mentioned corrigendum [1], an incorrect DOI was given for the original article [2]. This has now been corrected.

\section{References}

1. Stella A, Luz D, Piazza R and Spira B (2017) PpGpp and cytotoxicity diversity in Shiga toxin-producing Escherichia coli (STEC) isolates - CORRIGENDUM. Epidemiology and Infection 145(15), 3318-3318. doi: 10.1017/S095026881700200X.

2. Stella A, Luz D, Piazza R and Spira B (2017) PpGpp and cytotoxicity diversity in Shiga toxin-producing Escherichia coli (STEC) isolates. Epidemiology and Infection 145(11), 2204-2211. doi: 10.1017/ S0950268817001091. 